\title{
A Família entre o Público e o Privado
}

\author{
Cidinalva Silva Câmara Neris ${ }^{1}$
}

Resumo:

Este artigo discute a relação público/privado em matéria de família. Fruto do trabalho de tese, ainda em desenvolvimento, sobre as contradições que marcam a relação da regulação jurídica, as práticas judiciais e as práticas familiares, este artigo representa uma tentativa de se pôr em debate os processos de privatização e individualização dos comportamentos familiares e como esses mesmos processos são percebidos e/ou absorvidos pela regulação jurídica em matéria de família. Palavras-chave: Família; Público; Privado

\section{The Family Between Public and Private}

\section{Abstract:}

This article discusses the public / privacy relation in terms offamily issues. As a result of the ongoing thesis regarding the contradictions that emphasizes the relation of the legal regulation, the judicial practices and the family practices, this article is an attempt of bring into discussion the processes of privatization and individualization of family behaviors and how these same processes are perceived or absorbed by the legal regulation in terms of family issues.

Keywords: Family; Public; Privacy

\footnotetext{
${ }^{1}$ Graduada em História pela Universidade Federal do Maranhão (DEHIS/UFMA), Mestre em Ciências Sociais pelo Programa de Pós-Graduação em Ciências Sociais da Universidade Federal do Maranhão (PPGCSO/UFMA) e Doutoranda pelo Núcleo de Pós-Graduação e Pesquisa em Ciências Sociais da Universidade Federal de Sergipe (NPPCS/UFS). Email: cidinalvasilva@yahoo.com.br
} 


\section{Introdução}

Como bem destaca Jacques Commaille (1996) os modos de se analisar um dado fenômeno social depende fortemente das representações sociais feitas do objeto em um dado momento do desenvolvimento de uma sociedade. Isto é exatamente o que ocorre com os quadros de interpretações das relações familiares na contemporaneidade. É ponto pacífico entre os pesquisadores que se dedicam à análise e interpretação do tema que, no decorrer do século XX, principalmente entre as décadas de 1960-1970, a família ocidental passara por grandes transformações, acompanhado as modificações da sociedade moderna. Dentre essa mudanças apontam-se: a entrada maciça das mulheres no mundo do trabalho, tendo como consequências imediatas sua maior autonomia econômica, o que a levou a reivindicar modificações de seus papéis matrimoniais e sociais; maior instabilidade dos laços conjugais com o crescimento do divórcio e da concubinagem; o decréscimo dos casamentos e da natalidade, etc. Muitos, quando se referem a essas mudanças, identificam uma "crise" na instituição familiar, forma de interpretação ideologicamente localizada que tende a apontar um "modelo" de família dominante e ideal: a família nuclear, num primeiro momento, ou a família democrática como ocorre atualmente, vista como um espaço democrático, funcionando como suporte para a construção da individualidade de seus membros. Ao mesmo tempo, esse modo de interpretação, tende a caracterizar outras formas de organização familiar, como a família monoparental, por exemplo, como anormais, espaços onde as relações familiares se desenvolvem de forma precária, sendo essas famílias, geralmente, caracterizadas como desestruturadas.

Essa forma de interpretação, assim como de toda intervenção sobre a família, tem como referência um modelo de família formado por representações coletivas, científicas e jurídicas construídas pelas instituições e seus agentes que fundamentam um modelo de regulação, não só do familial, como também do social 
(COMMAILLE, 1996). É nesse sentido que os comportamentos familiares são aqui analisados, como inscritas na questão social, tendo em vista que, como afirma Claude Martin (1997, p. 17): “A família constitui um jogo político de primeira ordem, uma das instancia pelas quais a sociedade se reproduz a si mesma”. Assim sendo, a regulação das relações familiares e, em consequência, do divórcio, deve ser abordada através da relação entre público e o privado, entendendo que as formas de regulação jurídica das relações familiares são determinadas ao mesmo tempo em que determinam os jogos sócio-políticos de um dado contexto em uma época específica.

A família brasileira, seja como instituição ou como valor, seja em sua estrutura, formas de organização, sua relação com o mundo externo, sua função ou as formas de interação dos seus membros, é um objeto de estudo ao qual, historiadores, antropólogos e sociólogos vêm se dedicando a longas décadas, e, mais recentemente, psicólogos. Esse interesse, que permanece ao longo do tempo, vem mudando de forma, pois, é motivado pela tentativa de apreender as mudanças que ocorrem no seio da sociedade brasileira considerando que as relações familiares representam um lócus privilegiado de observação. Os estudiosos que se dedicam a analisar a produção acadêmica sobre a família brasileira ao longo do século XX identificam uma diversidade de abordagens e de questões orientadoras das pesquisas sobre o tema.

Como parte da tentativa de compreender a evolução da regulação jurídica das relações familiares na sociedade brasileira apresento aqui o esforço de mapear o debate sobre o processo de privatização das relações familiares, processo este, descrito pela maioria dos estudos como um traço marcante dos modos de interação das esferas pública e privada - a transformações das normas sociais, jurídicas e dos comportamentos marcadas pela maior autonomia individual. 


\section{O Público e o Privado}

Conforme Meulders-Klein (1992) a noção de vida privada emergiu na Europa e nos EUA por volta do século XIX, ascendo, após as duas guerras mundiais, ao estatuto de norma continental vindo a compor os direitos fundamentais. Segundo a mesma autora, a noção de privado, por natureza indetermina e híbrida, liga-se, em sua versão norte americana (privacy), à proteção da intimidade, da liberdade e do direito individual de existir. Já para na Conversão Europeia dos Direitos dos Homens, tal noção estaria ligada às relações individuais entre os membros da família. Em assim sendo, à noção de vida privada, apesar da grande diferenciação de uma concepção para a outra, estão interligadas duas questões fundamentais: a de indivíduo e a de regulação das ralações familiares. Portanto, a noção de vida privada pressupõe uma relação entre o privado e público, uma vez que estes são espaços interligados por uma produção mútua. Como se sabe, o espaço doméstico não se restringe ao âmbito íntimo do grupo familiar, está inscrito nas relações sociais, seu caráter privado só o é em relação com o espaço público.

Martine Segalen (1999, p. 306) desenvolve a ideia de que família funciona como elemento de mediação entre esferas privadas e públicas. Da mesma forma ela afirma que o Estado "produz a família através das definições jurídicas" e, ao mesmo tempo, o controle estatal sobre as relações familiares por meio do direito, sofre alteração "o próprio direito torna-se flexível e dá um lugar mais importante às opções individuais". É nesse sentido que o divórcio constitui um espaço privilegiado como ponto de partida da análise dos modos de interação entre o público e o privado pelo fato de que sua evolução recoloca, por um lado, a problemática das transformações do papel das práticas matrimoniais e parentais, ou seja, da relação conjugal e das relações de filiação, e de outro, as formas como essas transformações interagem com o conjunto de normas judiciais que buscam geri-las. Um exemplo disto são as formulações do divórcio no Direito da Família brasileiro que, desde sua liberação na década de 
1970, vem sendo modificando acompanhando as transformações das práticas familiares.

Desse modo, se a lei de 1977 exigia a separação judicial antes de efetivar o divórcio, isto é, o divórcio deveria ser indireto, a Ementa Constitucional 66/2010, eliminou essas exigências, permitindo que os casais se divorciem sem a necessidade de provarem que estão separados de fato a mais de dois anos e eliminando um vasto conjunto de procedimentos jurídicos. Assim também, a Constituição Federal brasileira de 1988, ao admitir a igualdade de direito entre os filhos havidos dentro e fora do matrimônio e outras formas de fundação da família para além do casamento, admitindo as uniões e fato e estendendo a estas todos os efeitos do casamento civil, está aceitando como regular antigas práticas sociais - como o concubinato por exemplo-, sinalizando mudanças na natureza e no status do matrimônio.

Clarice E. Peixoto e Vicenzo Cicchelli (2000), ao tratarem dos estudos de Antropologia e Sociologia da vida privada na Europa e no Brasil, título da apresentação de "Família e Individualização" da obra organizada juntamente a François de Singly, apresentam como principais transformações dos modos de funcionamento da família contemporânea, que dizem ser comum às sociedades ocidentais, uma progressiva abertura para a expressão pessoal e autonomia de todos os membros da família. Os autores afirmam que, apesar dessas transformações, que vão influir diretamente as relações entre a família e as demais esferas da sociedade, um quadro de permanências ainda garante à família o exercício de seu papel de centro de referência identitária de seus membros. Isso se deve ao fato da "família se manter como principal instituição de reprodução social e biológica; por continuar transmitindo entre as gerações seu estatuto social; e, por ultimo, por continuar desempenhando um papel central na manutenção da ordem social", ou como afirmam "uma ordem social desigual" (PEIXOTO \& CICCHELLI, 2000, p. 08). 
Além desse quadro de mudanças e permanências os supracitados autores destacam o crescimento da interação das esferas pública e privada, sendo a vida privada cada vez mais cruzada por mecanismos da esfera social num contexto onde os individualismos democráticos e românticos apresentam um dilema para as relações familiares: conformar a exigência de direitos iguais entre os cônjuges e de respeito às diferenças. Este dilema é uma das questões que permeia as pesquisas de François de Singly.

No que se refere à transformação das normas, como observa Martin (1997, p. 20) "a maior parte dos especialistas concordam por reconhecer uma neutralidade crescente do 'público' ao olhar a organização privada”. Tal neutralidade é interpretada em termos de um percurso na direção da privatização das relações familiares, sendo acionado pelo processo de individualização anteriormente descrito. Tendo em vista que o indivíduo exige o reconhecimento de sua autonomia, de seu direito de liberdade de escolher, toda forma de intervenção por meio de regras passa a ser entendida como uma afronta à sua individualidade. Desse modo, o direito tende a recuar e passa a adotar um modelo regulador gestacionário em substituição ao modelo prescritivo (Théry, 1998).

Segundo Commaille (1996), atualmente, a regulação jurídica das relações familiares está fundamentada num novo modelo, que não é restrito às questões familiares, mas, faz parte de todo um modo de regulação global do social, isto é, o modelo da "normatividade gestacionária". Tal normatividade, mais administradora dos efeitos dos comportamentos e menos produtora e impositiva dos modos de agir, está assentada na pluralidade das instâncias de regulação do social e na flexibilização do Direito. Como consequências dessa nova normatividade o autor aponta a crescente neutralidade do Estado na determinação dos comportamentos familiares e da independência do status jurídico do matrimônio; e, o crescente processo de privatização das relações familiares, ambos, fruto da maior hete- 
rogeneidade das relações familiares. Nesse sentido, nesse tipo de regulação do social, que gere as consequências das práticas, a privatização das relações familiares corresponderia aos modos de constituição, ao funcionamento e à dissolução do matrimônio, mas, não se estendendo aos efeitos resultantes dessa dissolução, posto que estes são de responsabilidade da esfera pública que, por meio da atuação dos operadores do direito, toma para si a coordenação da divisão dos bens e da organização dos papéis parentais no sentido de controlar os efeitos econômicos, psicológicos e sociais do fim do matrimônio.

Matine Segalen (1993) dedica a terceira parte de sua abra "Sociologia da Família" à análise da interação entre a ordem privada e a ordem pública. A autora busca demonstrar que a família situa-se na intersecção dos espaços público e privado, apresentando essa tese através da demonstração de como os espaços privado, por exemplo, a moradia, são determinados pela esfera pública através das políticas públicas de moradia e das normas de uso do espaço, da divisão espacial dos mercados de trabalho e imobiliário. Segalen demonstra também como a organização do espaço interno das residências retrata os modos como o privado se comunica como o público, defendendo a ideia de que: "não há domínio dependente do campo familiar- possivelmente exceptuando a vida profissional- que não revele também tanto do púbico. 0 habitat e as formas do habitado situam-se, pois, na intersecção do privado e do público" (SEGALEN, p. 279).

\section{Família, Individualização e Privatização}

Segundo Irène Théry (1998), as interpretações da mutação das relações familiares foram, até os anos sessenta do século XX, marcadas pela análise de três grandes transformações que caracterizam também a mutação da sociedade contemporânea ocidental: uma mudança de referência- a individualização; uma 
transformação das normas- a privatização e uma mudança dos modelos familiares - pluralização das relações familiares.

O processo de individualização, segundo Théry, opera um deslocamento do grupo familiar para indivíduo, onde este passa a ser visto como a célula base da sociedade, constituindo-se cada vez mais de forma autônoma em relação à família, ainda que inicialmente esta seja sua referência. Esta linha interpretativa é representada pelos estudos de François de Singly e traz em seu bojo um dilema, que Théry identifica como sendo seu principal limite: o equilíbrio entre as necessidades afetivas e os interesses materiais do indivíduo.

Nas pesquisas coordenadas por François de Singly, com uma clara pretensão de propor uma análise geral da família contemporânea ocidental, a questão principal gira em torno do desenvolvimento do individualismo, tema central para a teoria da família conjugal onde se localizam seus estudos. Observa-se nessa teoria a dialética da privatização/controle social, isto é, a relação estabelecida entre o indivíduo que se individualiza e um "Estado" que constrói as condições para que isso ocorra (DÉCHAUX, 1995).

Singly aborda a família em seu processo de autonomização da parentela e dependência do Estado, tese que navega na direção contrária à ideia de privatização das relações familiares. Nesse sentido, para ele: "A família contemporânea pode ser definida pelo peso de uma exigência específica, a demanda por parte dos homens e das mulheres de obter satisfações relacionais, afetivas no seio do casal, associado à demanda de um reconhecimento da personalidade de cada um dos filhos" (SINGLY, 1996, p. 58). Tais exigências, próprias do espaço privado, só podem ser feitas e satisfeitas, se assim o forem, pela instância responsável pela regulação dos comportamentos privados - o Estado. No prefácio da obra Família e Individualização Singly discorre sobre o processo de nascimento do "indivíduo individualizado" e seus efeitos na vida conjugal e familiar. 0 ponto de partida de sua argumentação 
é a afirmação de que, as sociedades ocidentais contemporâneas são marcadas por dois imperativos: o da construção da identidade pessoal original do indivíduo e do indivíduo autônomo. Tais imperativos, que levam Singly a considerar as sociedades ocidentais contemporâneas como "sociedades individualistas", seriam, segundo o mesmo, responsabilidades da família ou, mais propriamente, do casal conjugal e seus filhos. Em suas palavras, no contexto atual, "a família mudou para produzir esses indivíduos" (SINGLY, 2000, p. 14).

As transformações que Singly $(2007,2000)$ e vários outros autores destacam como marcas da família contemporânea, como por exemplo, o aumento do divórcio, da coabitação, a redução dos casamentos, etc., são por ele tomadas para ilustrar o nascimento do que nomeia de uma "família individualista e relacional", ou "família moderna 2", ou ainda de "família da segunda modernidade". Essa família seria o grupo social responsável por oferecer suporte ao indivíduo autônomo que não quer deixar de conviver com os demais.

A concepção de individualização apresentada por Singly (2007, 2000) não pressupõe um indivíduo egoísta que se forma sozinho, trancado em si, mas, um indivíduo que necessita interagir com o meio social, interligando a vida privada com a esfera pública, ou, como ele mesmo diz, trata-se de indivíduos que "(...) querem, ao mesmo tempo, ter asas e criar raízes" (SINGLY, 2007, p. 176). De fato, é a própria esfera pública, apresentada por Singly como "o Estado", que oferece suporte para que o processo de individualização ocorra e que a família o assuma, garantindo para cada um de seus membros um espaço privado onde possam se desenvolver. Desse modo, para Singly (2000, p. 15), esse espaço privado caracteriza-se "no nível da relação conjugal, pela maior independência das mulheres, a possibilidade de divórcio mútuo, (...), o fim da autoridade parental e, no nível da relação pedagógica, com o desenvolvimento da negociação das necessidades da criança, (...)”. 
Como se pode observar, os dois níveis de transformações que caracterizam a família "individualista relacional" de que fala François de Singly, o da conjugalidade e o da filiação correspondem exatamente às duas primeiras transformações das relações familiares às quais se refere Théry, a mudança da norma, que busca promover uma menor intervenção na relação conjugal; e a mudança de referência, que visa estender o controle público das relações entre pais e filhos por meio da ascensão da infância como foco das atenções sociais.

Jean-Hugues Déchaux (1995) faz uma crítica a essa perspectiva da individualização tutelado pelo Estado, defendida por Singly. Em primeiro lugar Déchaux reclama que, em vez de falar em "Estado", seria melhor Singly falar em esfera pública, visto que esta se faz de forma relacional com a privada, o que retiraria o peso da determinação do estado sobre a família já que as formas de intervenção da esfera pública na privada se dão de forma relacional e não por uma atitude passiva da família.

Outro ponto que gera certo desconforto nesse processo de individualização é que as transformações usadas para justificá-lo perecem estar muito mais ligadas a mudanças nos modos de produção econômica da sociedade moderna do que numa simples mudança psíquica dos sujeitos. Parece ser muito mais um feito da passagem de uma sociedade em que a família era a principal responsável pela reprodução econômica, através da transmissão da herança entre gerações, para uma sociedade assalariada. Além do mais, muitas pesquisas têm mostrado que o modo de reprodução assalariado não elimina a solidariedade familiar. Além disso, esse crescente processo de independência das trocas entre gerações precisa ser questionado frente à permanência das obrigações parentais que as relações familiares pressupõem.

Ainda que a família não tenha mais tanto peso na escolha do cônjuge, isso não significa que o grupo de parentesco não tenha nenhum tipo de influencia sobre essa escolha. A família continua 
exercendo um papel importante nas escolhas individuais, principalmente com a transmissão do capital cultural para as gerações mais novas, por meio dos espaços e das redes de socialização em que insere ou limita a participação de seus membros. Um exemplo disso é dado pelos estudos que continuam apontando um grande índice de homogamia na maioria dos grupos sociais.

Retomando a argumentação anterior, são exatamente os dois níveis de transformações que orientam a análise de Singly sobre a individualização: a transformação das relações conjugais e de filiação, que norteiam a discussão da relação entre o publico e o privado suscitado por várias pesquisas nas ciências sociais a partir da década de 1980, (BARTARD, 2002, 2006; COMMAILE, 1982a, 1982b, 1986, 1991, 1996, 2006/8; COMMAILE \& MARTIN, 1998; MARTIN, 1997; THÉRY, 1993,1998; SEGALEN, 1993; SINGLY, 2000, 2007; WEBER, 2005). Salvos as várias diferenças, tais pesquisas têm em comum, em maior ou menor grau, o esforço de compreender as formas pelas quais as transformações das relações familiares e das normas sociais se relacionam. Uma constatação comum é de que se desenvolveram, desde as ultimas décadas do século XX, por um lado, grande tendência à privatização dos laços conjugais, e, por outro, um crescimento da regulação dos efeitos dessa privatização. Desse modo, se a economia jurídica interna do privado é caracterizada pela contratualização das relações conjugais, portanto, dizem respeito às escolhas pessoais, seus efeitos são gestados pelo espaço público. Esses estudos acabam por demonstrar que, se o poder público está disposto a privatizar as relações conjugais, se mostra menos propenso a fazer o mesmo com as relações de filiação.

Segundo Théry (1993), a privatização da relação conjugal diminui a função da instituição matrimonial que deixa de ser o ponto de representação da família e do parentesco, uma vez que o casamento não é mais a única forma de constituição de uma família e nem mesmo o pressuposto para o reconhecimento da filiação. É no sentido de garantir que as relações 
de parentesco não se desestruturem, posto que provocariam efeitos na organização social, que as normas jurídicas contemporâneas tendem a controlar essas relações.

Segundo Clarice E. Peixoto, (2007) a ideia de privatização evocada por Théry a leva a concordar com a desinstitucionalização da família constatada por François de Singly, o que não me parece algo tão certo assim, visto que Théry constata que houve um processo de desvalorização da instituição do casamento enquanto única forma de fundação de uma família, mas, a família continua desempenhando um papel fundamental no desenvolvimento da criança.

Para Théry (1993), a transformação do status da conjugalidade é acompanhada de pela afirmação da responsabilidade parental, onde, se os laços conjugais estão sujeitos a se desfazer facilmente, há uma tentativa de tornar indissolúveis os laços de filiação. Assim, o fim do casal conjugal não significa o fim do casal parental.

Uma preocupação central da Commaille na obra "Misère de La famille: question d'État" é demonstrar que a transformação das relações familiares não se pôs em curso unicamente por uma mudança dos costumes, mas também, por uma transformação do mundo do trabalho e da regulação jurídica. É basicamente por meio do reconhecimento da filiação dos filhos havidos fora do casamento, que tem como consequência direta e imediata a aceitação da concubinagem, que a regulação pública das relações privadas pôs em curso o reconhecimento jurídico de outras várias formas de constituição da família que já eram presentes nas práticas sociais. A admissão jurídica de outras formas de constituição da família que não por meio do casamento se deve a fatores variados, mas que estão ligados a duas questões: por um lado as transformações econômicas que promoveram a maciça entrada das mulheres no mundo do trabalho assalariado, motivando uma transformação do status da mulher, e às modificações na divisão do trabalho doméstico, por outro, a ascensão da infância como pedra angular das relações familiares e alvo de cuidados sociais. 
No momento que os modos de produção econômica da sociedade moderna se modificam, tornando-se cada vez mais complexos, o mesmo ocorre com a reprodução econômica das famílias surgindo condições para que a divisão dos papéis no interior da família se modifique, podendo essas condições apresentarem-se como imperativas, o poder público vai perdendo condições de determinação dos comportamento sociais que passam e ser reclamados por diversas instancias de regulação social. Desse modo, o direito também se modifica, perde seu poder de prescrição e incorpora um viés cada vez mais de gestão.

Jacques Commaille (1991, p.40) propõe um "modelo de análise da legalidade em matéria de família" dividido em três níveis analíticos, níveis estes que estão estreitamente ligados às configurações sociais, econômicas, culturais, políticas e jurídicas. Primeiramente é destacada a necessidade de se abordar o que denomina de "economia jurídica interna do privado", caracterizada pelo "fenômeno da contratualização das relações familiares". Esse processo pode ser observado, por exemplo, nas leis do divórcio, na forma de gestão dos bens da família, na guarda compartilhada dos filhos, com a instauração da autoridade parental, etc., Esse fenômeno, segundo compreende o autor, colocou em evidência a ideia da igualdade dos parceiros nas relações conjugais e a indiferença da natureza jurídica da família ou do fundamento do casal no que se refere à regulação de suas relações "onde o contrato não é mais uma expressão de uma aliança entre duas famílias, mas, a simples garantia de uma relação igualitária” (COMMAILLE, 1991, p.40).

O primeiro nível de análise de Commaille (1991, p. 41) o leva a concluir sobre a constatação da contratualização das relações familiares se afirma num movimento em que uma nova norma social dominante, correspondente a novos modelos matrimonias, fará sua transcrição numa norma jurídica consagrando esse modelo da contratualização qualquer que seja o status jurídico do casal ou da família. 0 segundo nível da proposta de Commaille 
trata da relação do privado com o público, onde ele constata a crescente privatização das relações familiares. Esse fenômeno é explicitado pelo autor através da legalização da coabitação sem casamento. Mas, ele alerta que essa regulação dos efeitos dos comportamentos da família, diz respeito apenas seus modos de constituição, funcionamento e dissolução, pois, há uma crescente preocupação no que tange aos resultados desses processos nas políticas de gestação das populações. Para Commaille essa privatização das relações familiares está ligada a uma transformação do próprio poder normativo, ao processo de socialização do direito que transferiu a competência, em matéria de relações familiares, "do público, da família para o indivíduo" (COMMAILLE, 1991, p. 42). O resultado desses processos foi a individualização na socialização do direito.

O terceiro nível de análise da proposta de Commaille busca compreender a regulação das relações familiares no conjunto das "normatividades da sociedade global", tendo em vista que uma normatividade não diz respeito somente às relações familiares, mas, a todo um modo de funcionamento mais global das regulações jurídicas. Dessa forma, a transformação das regulações no que trata à família, com um caráter muito menos prescritivo e mais negociável, é resultado da transformação das "regulações tradicionais marcado por um novo modelo de gestação das relações sociais- negociação permanente. (...) a passagem de uma legalidade menos referencial para uma mais gestacional". (COMMAILE, 1991, p. 43-44). Tal normatividade, mais administradora dos efeitos dos comportamentos e menos produtora e impositiva dos modos de agir, está assentada na pluralidade das instâncias de regulação do social e na flexibilização do Direito. Como consequências dessa nova normatividade o autor aponta a crescente neutralidade do Estado na determinação dos comportamentos familiares e da independência do status jurídico do matrimônio; e, o crescente processo de privatização das relações familiares, ambos, fruto da maior heterogeneidade das relações familiares. 
Nesse sentido, nesse tipo de regulação do social, que gere as consequências das práticas, a privatização das relações familiares corresponderia aos modos de constituição, ao funcionamento e à dissolução do matrimônio, mas, não se estendendo aos efeitos resultantes dessa dissolução, posto que estes são de responsabilidade da esfera pública que, por meio da atuação dos operadores do direito, toma para si a coordenação da divisão dos bens e da organização dos papéis parentais no sentido de controlar os efeitos econômicos, psicológicos e sociais do fim do matrimônio.

Em "Famille sans Justice? Le droit et la justice face aux transformations de la famille", Commaille analisa a relação entre as mudanças das relações familiares e seu tratamento jurídico partindo "da entrada no casamento; a situação da mulher e da criança; a saída momentânea do casamento, o divórcio e as trocas" (SINGLY, 1984). Na relação entre mutação das relações familiares e transformações no direito Commaille (1982) salienta que o direito intervém na esfera familiar segundo duas lógicas: a lógica jurídica, da normatividade, que trata da definição dos princípios legais norteadores das práticas familiares e a uma lógica social onde podem ser percebidos os efeitos sociais da transformação nas práticas familiares.

Essas transformações exigem um direito baseado numa representação de família que, segundo Commaille (1996, p. 26), "ainda é a representação de uma família tradicional”. É com base nessa representação e na tentativa de manter esse modelo como dominante que o direito da família vai incluindo aos poucos as reivindicações dos grupos sociais e normalizando relações excluídas da regulação jurídica. Desse modo, o público não abre mão de regular as relações familiares, pelo contrário, estando o direito civil responsável pela manutenção da ordem pública, suas intervenções nas relações familiares não estão voltadas para a proteção de direitos individuais ou não, mas, para a gestão dos modos de reprodução social. E, nessa matéria a família mantém um papel central. Por outro lado, as formas de regulação jurídica da família 
também pressupõem um tipo de indivíduo: aquele capaz de estabelecer uma relação democrática com os demais, de cobrar seus direitos e cumprir seus deveres. No entanto, a utopia do indivíduo autônomo não pode garantir que todos, independente de suas especificidades, econômicas, sociais e culturais, tenham as mesmas condições de imposição e reconhecimento.

Porém, o acúmulo dessas transformações resulta na imposição de nova imagem da família. Desse modo, a família perde sua função tradicional de reprodução econômica e passa a ser pensada como responsável pela realização pessoal de seus membros. A interpretação das relações familiares em termos desta tripla transformação tem orientado a constituição das representações sociais sobre a família e os modos do Estado intervir nas relações familiares. Elas desconsideram as diferenças de condições que cada grupo social tem de ser afetado pelas transformações sócio-políticas, desconsideram principalmente as desigualdades sociais, de idade, de sexo e econômicas que criam condições diversas dos indivíduos se relacionarem nos mais diversos grupos e espaços.

Segundo Martine Segalen (1999) a instituição familiar é uma carta que se joga entre cidadãos e o Estado. Esta afirmação faz muito sentido quando nos deparamos com a preocupação de nossa legislação em definir o lugar e os papéis da família na sociedade brasileira como, por exemplo, a Constituição Federal de 1988 que a define como "base da sociedade", portanto, alvo de "especial proteção do Estado". Nas definições de família estão envolvidas visões de mundo e formas de hierarquização jurídicas e judiciais das instituições sociais. Não devemos desconsiderar que, como afirma Remir Lenoir (2005, p. 209, tradução nossa): “Graças a uma equação socialmente predeterminada entre as categorias políticas e familiares de percepção do mundo social as estruturas familiares estão reconhecidas como os cimentos de todas as coisas, particularmente da coisa pública". 
Desse modo, uma análise sociológica da família contemporânea far-se-á mais completa na medida em que considerar as complexidades das relações entre transformações familiares e transformações sociais e, ao mesmo tempo, considerar que nas definições e nas intervenções jurídicas da organização familiar estão em jogo tentativas de manutenção da própria ordem social através das instituições que a constituem. Como diria Lenoir (2005, p. 210, tradução nossa) “(...) trata-se, na realidade, da estrutura e da hierarquia das instituições que contribuem para a reprodução da ordem social." Além disso, as relações familiares são marcadas também por hierarquias e desigualdades, o que não aparece no processo de individualização descrito por Singly.

Diferente da constatação de Lenoir, a teoria da primazia do casal como apresentada por Singly, centrada na psicologização das relações familiares, supervalorizando a individualização, tende a caracterizar a família como um espaço apenas de apoio afetivo e psíquico, excluindo o peso das lutas econômicas, de gênero, geracionais e parentais que tornam o modo de relação de cada grupo familiar único.

Como processo de individualização se comporta no Brasil é uma das questões que se coloca nesta pesquisa. Apesar de havermos poucos estudos voltados para esta questão, podemos afirmar que a individualização é um fato que se apresenta a posteriori, inclusive como forma de demonstrar a transformação da família patriarcal e a afirmação da família nuclear e democrática. Esses estudos são influenciados por uma leitura da sociedade brasileira a partir do processo de modernização. Do mesmo modo, pelas análises realizadas por Antony Giddens e François de Singly de como a modernidade se afirma e é ultrapassada no mundo ocidental.

A esse respeito Lira Machado (2001), busca problematizar a pertinência da abordagem da família brasileira partindo da individualização como pressuposto dos modos de organização das famílias 
brasileiras. Como modo de ultrapassar essa perspectiva, Machado (2001.p. 16) sugeri "a coexistência de um código relacional ancorado nas noções de honra, reciprocidade e hierarquia e de um código individualista" que atravessam toda a organização social, sendo que a hierarquia tem forte peso sobre as relações familiares. Marchado defende ainda a ideia de que é a presença desses dois códigos que marca a especificidade dos modos de organização dos arranjos familiares brasileiros diante do "mundo ocidental central".

Socott (1999), ao localizar os estudos antropológicos sobre a família brasileira entre as tradições "subjetivista" e "econômico-produtivista", destaca que esses estudos têm como pano de fundo a relação entre o público e o privado, observável através dos modos de organização dos arranjos familiares, em suas maneiras de se relacionar com o Estado, seja através das normas jurídicas, seja por meio das políticas públicas direcionadas às famílias ou através da compreensão de suas relações com o mundo do trabalho. Sendo este ultimo aspecto o mais relevante para os estudos criticados por Scott (1999).

Scott diz que esses estudos promovem uma inversão entre o público e o privado. Assim, se todos concordam que o grupo familiar media a relação dos indivíduos com o mundo externo, os modos como essa mediação é feita é diferenciada entre os grupos sociais. Se as reflexões sobre as famílias das camadas pobres urbanas partem de fora para dentro, as famílias da camada médias são pensadas a partir de sua organização interna, do processo de individualização. Neste grupo "o debate coloca os projetos individuais e coletivos a cima da autoridade e seus efeitos"(SCOTT, 1999. p.82). Assim sendo, neste seguimento, o privado invade o público. Por outro lado, a relação entre o público e o privado das famílias desfavorecidas se organizaria a partir da extensão da dominação que sobrem na esfera pública. Os estudos sobre esse seguimento destacam a solidariedade como meio de enfrentamento das situações com que se deparam esses arranjos em sua relação com a esfera pública. 
Independentemente do ponto de observação escolhido pelo pesquisador para analisar a família brasileira, observamos neles traços comuns, dentre os quais podemos citar: tomar a ideia de diversidade das formas familiares como paradigma fundamental e a ênfase sobre o suposto embate entre o individuo e o grupo familiar como característica marcante da família brasileira contemporânea. A esse respeito Machado (2001, p. 12) distingue os estudos em dois conjuntos: um que fundamenta a análise da "diversidade de formas de familiares, a retração ou expansão do valor e do lugar da família numa sociedade, a um paradigma cultural fundante" e outro que atribui a diversidade de formas familiares e dos valores a elas atribuídos "a diversas causas e contextos dentre os quais estão os modos de intervenção do Estado".

O problema apontado por Machado (2001) nas duas interpretações é o exercício de um embate entre o que ela chama de "familismo", identificado como característica marcante da sociedade colonial brasileira e o "individualismo", processo que norteia as interpretações das configurações familiares em vários países, principalmente os europeus e os Estados Unidos. A crítica feita por Machado a essas duas perspectivas é que ambas buscam interpretar as famílias brasileiras partindo do familismo - uma configuração que é questionável, inclusive para o período em que ela é dada como uma certeza, - o Brasil colonial- ou a partir do individualismo- uma configuração externa à nossa sociedade e que deve ser problematizada inclusive para as interpretações dos locais de onde vêm, pois, como destaca: "nada há de seguro e inercial na longa duração do favor da família no Brasil, ou de garantia na pretendida crença de que o individualismo das sociedades desenvolvidas reforme, em só sentido linear o futuro das formas e os valores da família" (MACHADO, 2001, p. 12).

Com efeito, as análises das formas familiares no Brasil contemporâneo, inspiradas em estudos que põem em confronto a família enquanto instituição e valor e o crescente processo de individualização no mundo ocidental resulta num obstáculo analítico 
se não levarmos em conta a própria complexidade desses processos e as desigualdades sociais, raciais, geracionais, regionais e que marcam atualmente nossa sociedade. 0 problema com o imperativo do individualismo reside no fato de que ele é visto como um valor que vai substituir o valor da família como instancia de mediação entre as esferas pública e privada em todas as camadas sociais, visto como um percurso único para os países ocidentais. A questão aqui não é negar o processo de afirmação do individuo, o problema está na tentativa de generalização da interpretação dos modos como ele ocorre para um nível global, principalmente no caso brasileiro, uma sociedade extremamente desigual e em que os direitos da cidadania igualitária e individual pouco se difundiram.

Lira Zanotta Machado identifica duas diferenças entre os modos pelos quais se processa o individualismo na Europa e nos Estados Unidos e como ele se coloca no Brasil. Por um lado, no Brasil, não se desenvolveu um Estado de bem-estar social e nem se generalizaram os direitos dos cidadãos e, por outro, a noção de indivíduo, a organização da família e os modos de sociabilidade são informados por um paradigma cultural não enraizado na autonomia do individual. Com base nessas constatações Machado critica as pesquisas herdeiras das noções de individualização de Antony Giddens e François de Singly que defendem o crescimento do valor individuo em detrimento do valor família, especificamente nas famílias das camadas médias brasileiras. A esse respeito, Roberto da Matta (198, p. 1327) chama nossa atenção para o fato de que, ao contrário do que ocorreu nos países europeus, em que a família teve suas funções política e econômica reduzidas e o tipo nuclear generalizou-se, no Brasil "permanecem as relações entre os grupos e não se instituiu qualquer forma hegemônica". Além disso, como enfatiza da Matta, as manifestações individualizantes na sociedade brasileira estão muito bem localizadas e só são possíveis graças a uma rede de relações que lhes oferecem suporte. 


\section{Considerações Finais}

Jacques Commaille, em "L'économie sócio-politique des liens familiaux" (2006), aponta como constatação a tendência de autonomização como característica dos laços familiares em relação às lógicas de regulação publica, mas, destaca que a economia desses mesmos laços é posta em prática por indivíduos inscritos em lógicas dos espaços públicos "determinados por injunções políticas” (2006, p.173). Ou seja, os comportamentos dos indivíduos no espaço privado são inspirados pelo universo público, pois, resultam das múltiplas interações dele no espaço público onde ele se formula e reformula as bases daquilo que lhe define socialmente enquanto pessoa tendo como referencia o gênero, a idade, a atuação profissional, etc.

Desse modo, apesar da constatação da tendência de autonomização dos laços familiares em referencia ao espaço público, não podemos esquecer que ambos os espaços se constroem de forma interacional e que, portanto, exercem influencias múltiplas entre si. É por isso que Commaille (2006) destaca a necessidade de se buscar compreender as influências que o mundo social exerce sobre os laços familiares. Nesse sentido, ele observa que a forma mais visível dessa influencia está na "reprodução da estratificação social dos laços familiares" (COMMAILLE, 2006, p. 174).

É evidente, portanto, que os processos de individualização/privatização devem, antes de tudo, ser problematizado. Cabe então, questionar: quando de fala de privatização, fala-se de quê? 0 que o estado está disposto a privatizar e o que não está? Se os sujeitos estão dispostos a decidir suas relações privadas, por que buscam cada vez mais o papel mediador das leis? Em que contexto pode-se falar em individualização? Pode-se falar naqueles onde as trocas familiares entre membros e gerações são partes integrantes da estrutura do grupo familiar, como apontam os estudos sobre as famílias de classe popular no Brasil? Ambas as 
abordagens, individualista e familialista, não estão, novamente, tentando promover de um tipo ideal de família? Que tipo seria esse? Essas são apenas algumas questões que poderão nortear minha pesquisa em curso.

\section{Ref erências Bibliográficas}

BARTARD, B. Les démarieurs: enquête sur les nouvelles pratiques du divorce. Paris. La Découverte, 2002.

Une nouvelle police de la parenté? In : Enfances, Familles, Générations. Numéro 5, automne 2006, p.1-9. http://www.erudit.org/revue/ efg/2006/v/n5/015783ar.html, 2006.

BASTERD, L. L. Permanência ou mudança? 0 discurso legal sobre a família. In: ALMEIDA, A. M. de. et. al. (orgs.). Pensando a família no Brasil: da colônia à modernidade. RJ: Espaço e Tempo: UFRRJ, 1987.

BOURDIEU, P. A força do direito: elementos para uma sociologia do campo jurídico. In: 0 poder simbólico. 11aㅡ ed. Rio de Janeiro; Bertrand Brasil, 2007.

Da regra às estratégias. In: BOURDIEU, P. In. Coisas Ditas. São Paulo: Editora Brasiliense, 1990.

À propos de la famille comme catégorie réalisée. In: Actes de la recherche en sciences sociales. Vol. 100, p. 32-36, décembre 1993.

Esboço de uma teoria da prática: precedido de três estudos de etnologia Cabila. Lisboa: Celta, 2009.

BILAC, E. D. Sobre as transformações nas estruturas familiares no Brasil. Notas muito preliminares. In: DUARTE, L. F.et. al. Família em processos contemporâneos: inovações culturais na sociedade brasileira. São Paulo: Loyola, 1995.

CHEVALLIER, J. La régulation juridique en question. Droit et Société, $n^{\circ}$. 49, 2001.

COMMAILLE, J. Le Divorce en Europe occidentale: la loi et le nombre. International Research Group on Divorce, Centre d'étude de théorie et d'évaluation législatives (Geneva, Switzerland), 1982a.

Familles sans justice?:le droit et la justice face aux transformations de la famille, Paris. Le Centurion,1982b. 


\section{Cidinalva Silva Câmara Neris}

D'une sociologie de la famille à une sociologie du droit. D'une sociologie du droit à une sociologie des régulations sociales. Sociologie et sociétés, vol. 18, n 1, p. 113-128,1986.

Nouvelle légalité et modes d'anályse des comportements familiaux. In. HIBERT, T. ; ROUSSEL L. La nuptialité, évolution récente en France et dans les pays développés. Édictions l'Institut National dÉtudes Démographiques, 1991.

Misères de la famille. Question d'État. Paris, Presss de la Fundation nationale des sciences politiques, 1996.

Prefácio. In. MARTIN, C. L’après divorce. Lien familial et vulnérabilité. Rennes, Presses Universitaires de Rennes, 1997.

La famille, l'état, le politique: une nouvelle économie des valeurs. Entre tensions et contradictions. Caisse nationale des Allocations familiales Informations socials 2006/8 - N 136, 2006.

L'économie socio-politique des liens familiaux. ERES, Dialogue. 2006/4 - no 174, pages, 95 à 105, 2006.

; MARTIN, C. Les enjeux politiques de la fammille. Paris, Bayard, 1998.

CORRÊA, M. Repensando a família patriarcal brasileira. In: ALMEIDA, M. S. K. de. etall (orgs). Colcha de retalhos. SP, Brasiliense, 1982.

FONSECA, C. W. Olhares Antropológicos sobre a família contemporânea. Cadernos de Direito Previdenciário, 2007. Disponível em:-www.trf4.jus.br/ trf4/upload/editor/hba_CLAUDIA_FONSECA.pdf.

GOLDANI, A. M. As Famílias no Brasil Contemporâneo e o Mito da Desestruturação. Cadernos Pagu n. 1, Campinas, IFCH. Unicamp, p. 67-110. Disponível em: http://www.pagu.unicamp.br/node/40,1993.

As famílias brasileiras: mudanças em perspectiva. Ca. Pesq., São Paulo, n. 91, p., 7-22, Nov, 1994.

GOMES, J. V. Família popular: mito ou estigma? In. Travessia. Jan/abr/91. № 5, 1991.

LAURIS E. Entre o social e o político: a luta pela definição do modelo de acesso à justiça em São Paulo. In. Revista Crítica de Ciências Sociais, 87, Dezembro 2009: 121-142, 2009.

LENOIR, R. La genealogia de la moral familiar. In: Política y Sociedade, vol. 42, N. 3: 209-225, 2005.

MACHADO, L. Z. Famílias e individualismo: tendências contemporâneas no Brasil. In. Interface - Comunic, Saúde, Educ 8, 2001. 
MEULDERS-KLEIN, M.-T. Vie privée, vie familiale et droits de l'homme. In: Revue internationale de droit comparé. Vol. 44, n . 4, Octobre-décembre 1992. pp. 767-794, 1992.

PEIXOTO, C. E; SINGLY F. de; CICCHELLI, V. (Orgs.). Família e Individualização. tradução de Ângela Xavier de Brito. Rio de Janeiro: Editora FGV, 2000.

PEIXOTO, C. E. As transformações familiares e o olhar do sociólogo. In: SINGLY, F. de. Sociologia da família contemporânea. Rio de Janeiro: FGV Editora, 2007.

; CICCHELLI, V. Sociologia e antropologia da vida privada na Europa e no Brasil. Os parados da mudança. In. PEIXOTO, C. E; SINGLY F. de; CICCHELLI,V. (Orgs.) Família e Individualização. Apresentação. Tradução de Ângela Xavier de Brito. Rio de Janeiro: Editora FGV, 2000.

ROMANELLI, G. Mudança e transição em famílias de camadas médias. In. Travessia. Jan/abr/91. № 5, 1997.

SAMARA, E. de M. A família Brasileira. São Paulo: Brasiliense, 1983.

A história da família no Brasil. Rev. Bras. de Hist. Apresentação. São Paulo. V .9, no 17, PP. 07-37, set.88/fev98, 1988.

A família no Brasil: história e historiografia. História Revista, 2(2) : 07-21. Jul/dez. 1997.

SCOTT, R. P. Travail, puvoir et inversion du public et du privé: ethnografie de la famille urbaine au Brésil. Cahiers du Brésil Contemporain, no 31, p.69-88, 1997.

SINGLY, F. de . La famille et le droit d'après Jacques Commaille. In: Revue française de sociologie. 1984, 25-1. pp. 135-140, 1984.

Sociologia da família contemporânea. Rio de Janeiro, FGV editora, 2007.

THÉRY, I. Couple, filiation et parenté aujourd'hui: le droit face aux mutations de la famille et de la vie privée. Paris, Editions Odile Jacab, 1998.

Le Démariage. Justice et vie privée. Paris, Odile Jacob, 1993.

VELHO. G. Família e Subjetividade. In. ALMEIDA, A. M. de, et. al. (Orgs.). Pensando a família no Brasil: da colônia à modernidade. Espaço e Tempo: UFRRJ, 1987.

WEBER. F. Le sang, le nom, le quotidien: une sociologie de la parenté pratique. Aux lieux d'être, 2005.

WIDMER, É. ; KELLERHALS, J. ; LEVY. R. Quelle pluralisation des relations familiales? Conflits, styles d'interactions conjugales et milieu social. Revue française de sociologie, 2004/1 Vol. 45, p. 37-67, 2004. 
WOORTMANN, K. A etnologia (quase) esquecida de Bourdieu, ou o que fazer com heresias. In: Revista Brasileira de Ciências Sociais, ano/vol. 19, número 056, São Paulo, p. 129-137, 2004.

Recebido em 19.10.2011.

Aprovado em 29.11.2011. 